\title{
Was tun, wenn ein Patient nicht zahlt?
}

Die Rechtsfrage

» Ein Privatpatient hat nach abgeschlossener

Behandlung seine Rechnung von 672 Euro nicht

bezahlt. Daraufhin habe ich geklagt und bekam

vom Amtsgericht ein Anerkenntnisurteil zuge-

sprochen. Seitdem (Mai 2011) bitte ich den

Patienten, der von ihm vorgeschlagenen Raten-

zahlung nachzukommen. Ohne Erfolg. Wie

komme ich nun an mein rechtmäßiges Geld? «

Physiotherapeutin aus Bayern

\section{Die Antwort unseres Experten}

Dass Kunden ihre Rechnungen nicht bezahlen, ist in vielen Bereichen ein Problem. Die gerichtliche Bestätigung, dass die Zahlungsforderung rechtens ist, ist hierbei jedoch nur eine Seite der Medaille. Denn das Urteil ist lediglich ein Dokument, das dem Gläubiger die Forderung tatsächlich zuspricht. Wie bei Ihnen stellt sich dann aber die Frage, was weiter geschehen muss, damit Sie das geschuldete Geld auf dem Konto sehen. Für solche Fälle gibt es das Vollstreckungsverfahren. Darin setzen staatliche Organe wie ein Gerichtsvollzieher oder ein Vollstreckungsgericht das Urteil gegen den Schuldner durch - im Zweifel auch gegen dessen Willen. Geldforderungen vollstrecken sie beispielsweise mithilfe einer Taschenpfändung. Dabei darf der Gerichtsvollzieher alle möglichen beweglichen Gegenstände und Bargeld in Besitz nehmen.

Liegt - wie in Ihrem Fall - ein Anerkenntnisurteil vor, muss man bei Gericht die „Vollstreckbare Ausfertigung des Urteils“ beantragen. Mit dieser Ausfertigung wendet man sich an die Vollstreckungsbehörde, also an den Gerichtsvollzieher oder an das Vollstreckungsgericht. Gerichtsvollzieher sind für Taschenpfändungen zuständig, das Vollstreckungsgericht für den Erlass von Pfändungs- und Überweisungsbeschlüssen, zum Beispiel Kontopfändungen. Wenn es sich um kleinere Forderungen handelt, beauftragt man am besten den Gerichtsvollzieher mit der Pfändung. Dazu schickt man den Antrag zur Durchführung der Vollstreckung samt vollstreckbarer Ausfertigung des Gerichtsdokuments an die Gerichtsvollzieherverteilerstelle des für den Schuldner zuständigen Amtsgerichts. Liegt eine Kontoverbindung vor, kann man einen Erlass für einen Pfändungs- und Überweisungsbeschluss beim Vollstreckungsgericht beantragen. Einen solchen Vollstreckungsantrag sollte man jedoch von einem Anwalt stellen lassen, da zu den Forderungen regelmäßig auch Zinsen und Kosten hinzukommen, die man in einer Forderungsaufstellung zusammenfassen muss.
Die Durchsetzung von Forderungen ist also mit einem Gerichtsurteil noch nicht zu Ende. Vielmehr bedarf es eines weiteren Vollstreckungsverfahrens. Wer dieses nicht durchführt, darf sich nicht wundern, wenn er das ihm zustehende Geld trotz eines vorliegenden Urteils nicht bekommt. Mit ein bisschen Glück kann so ein Verfahren in zwei Monaten abgehandelt sein. Stellt sich der Schuldner quer oder ist noch ein Berufungsverfahren nötig, können auch mehrere Jahre vergehen. Davon sollte man aber bei relativ überschaubaren Forderungen nicht ausgehen. Was die Kosten angeht, so trägt der Schuldner - wenn er unterliegt sämtliche Kosten des Gläubigers plus Zinsen. Ein Tätigwerden lohnt sich daher fast immer. Es sei denn, es geht um minimale Forderungen, die den zeitlichen Aufwand nicht lohnen, oder der Schuldner hat erkennbar kein Geld. Philipp Groteloh

\section{$\rightarrow$ Wirft auch Ihr Berufsalltag rechtliche Fragen auf? Dann schreiben Sie an Simone.Gritsch@thieme.de.}

